\title{
Fatigue-Crack Propagation of High-Density Polyethylene Homopolymers: Influence of Molecular Weight Distribution and Temperature
}

\author{
Robin R.J. Cerpentier, Tim van Vliet, Leonid V. Pastukhov, Martin van Drongelen, Mark J. Boerakker,
} Theo A. Tervoort,* and Leon E. Govaert*

Cite This: Macromolecules 2021, 54, 11508-11521

Read Online

ABSTRACT: The present study focuses on the influence of the molecular weight distribution (MWD) on the crack-growth kinetics of fatigue-crack propagation in highdensity polyethylene (HDPE) homopolymers. Compact-tension specimens of HDPE homopolymer grades, with polydispersities ranging from 2 to 45 and weight-averaged molar mass ranging from 49 to $450 \mathrm{~kg} / \mathrm{mol}$, are tested in cyclic loading at temperatures ranging between 23 and $92{ }^{\circ} \mathrm{C}$. Through a variation of sample thickness, linear elasticfracture mechanics is shown to apply for the chosen geometry (compact tension). It was found that the crack-propagation kinetics obey the Paris-Erdogan law, for which the Paris-Erdogan exponent $m$ is (highly) similar for all grades tested $(m=3.9)$, implying that the Paris-Erdogan prefactor $A$ is the governing parameter for the crack-growth kinetics. Relatively poor correlations are observed when the prefactor $A$ is plotted as a function of both the tie-molecule fraction derived from the theoretical model by Huang and Brown, J. Mater. Sci. 1988, 23, 3648, and the average number of effective physical cross-links per chain as derived by Tervoort et al., Macromolecules 2002, 35, 8467. A far better correlation is observed between prefactor $A$ and the weight-average molecular weight $\left(M_{\mathrm{w}}\right)$, which improved further when $M_{\mathrm{w}}$ is corrected for the width of the MWD, taking into account the z-average molecular weight $M_{\mathrm{z}}$, through the ratio $M_{\mathrm{z}} / M_{\mathrm{w}}$. A power-law correlation of prefactor $A$ with $M_{\mathrm{w}}$ and the width-corrected $M_{\mathrm{w}}$ reveals slopes of -3.4 and -3.3 , respectively. Because a molecular slip within the fibrils would require chain transport through the crystalline blocks, the temperature dependence of the fatigue-crack-growth kinetics is investigated to identify the underlying molecular processes. This investigation reveals the existence of a high-temperature and a low-temperature deformation process, both of which can be related to chain-slip mechanisms through their respective activation energies (125 and $50 \mathrm{~kJ} / \mathrm{mole}$ ), as their activation energies are considerably lower than that required for chain scission $(430 \mathrm{~kJ} / \mathrm{mol})$. This, combined with the power-law exponent of -3.4 , would suggest a possible connection between the underlying failure mechanisms of craze fibrils and reptation-like dynamics. Furthermore, experiments at elevated temperatures on a selection of homopolymer grades suggest that the MWD has no influence on the temperature dependence of fatigue-crack propagation for HDPE homopolymers.

\section{INTRODUCTION}

Since its discovery in the 1950's, high-density polyethylene (HDPE) has seen increasing use in pressure-pipe applications for water and gas transport. ${ }^{3,4}$ Regarding their long-term use in these applications, information about their lifetime under stress is of great relevance. This is usually expressed by the term "Minimum Required Strength", the extrapolated stress at which failure occurs after 50 years at room temperature, which is used in the classification of polyethylene pipe grades. ${ }^{5-7}$ It is well known that the long-term failure properties of HDPE pipes are controlled by three distinct failure mechanisms: (I) plasticity-controlled failure, (II) crack-growth-controlled failure, and (III) degradation-controlled failure. ${ }^{5-7}$ These failure mechanisms work simultaneously on the material, until ultimate failure is triggered through one of them. ${ }^{5,8,9}$ However, developments in stabilizer systems have greatly improved the chemical stability of HDPE pipe grades and hence degrada- tion-controlled failure is no longer regarded as a limiting factor in the long-term application of HDPE. ${ }^{3}$

In the past, crack-growth-controlled failure has been at the center of most investigations into long-term failure of polyethylene because failure at large timescales (50 years or more) was almost exclusively due to this type of failure. ${ }^{1,9-12}$ However, since the introduction of bimodal pipe grades, the (extrapolated) slow crack-growth mechanism has shifted to timescales beyond the service lifetimes required for pressure

Received: September 14, 2021

Revised: November 14, 2021

Published: December 8, 2021

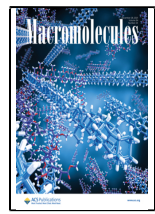


pipe applications. ${ }^{10,13}$ Therefore, studies into the plasticitycontrolled failure mechanism (and the material parameters that influence this failure type) have become more relevant. ${ }^{13,14}$ Investigations into the material parameters that affect plasticity-controlled failure, nevertheless, have shown that crystallinity has a considerable influence on this failure mechanism. ${ }^{15,16}$ Furthermore, it was shown that the introduction of short-chain branches limits the degree of crystallinity of HDPE. ${ }^{17}$ Hence, the use of co-polymerization in bimodal pipe grades, which greatly improves resistance to crack-growth-controlled failure in certification tests, is a limiting factor in the resistance to plasticity-controlled failure. Moreover, increases in crystallinity, while beneficial for plasticity-controlled failure, have shown to be detrimental for crack-growth-controlled failure. ${ }^{9}$ This has led to a situation where the optimization of the material properties for either of the failure mechanisms leads to a sub-optimal performance with regard to the other mechanism. Hence, in order to raise the minimum required strength of polyethylene pipe grades successfully, a more detailed investigation of the effect of morphological and molecular parameters on the failure mechanisms is needed.

In the present study, the focus will be directed to the crackgrowth-controlled failure process. When slow crack growth is studied on a microscopic scale, it can be seen that, after the initiation of crack growth, the crack-growth kinetics are controlled by the formation and breakdown of the craze in front of the crack. ${ }^{9,18-20}$ This craze consists of highly oriented craze fibrils, which deteriorate and elongate under stress until they break, forming the fracture surface in the process. ${ }^{19,20}$ While both the formation and breakdown of the craze have an influence on the crack-growth kinetics, breakdown of the craze is usually the rate-determining step in the crack-growth process. ${ }^{1,11,19}$ This places additional emphasis on (molecular) parameters that influence the breakdown of the craze fibrils, as the deceleration of fibril breakdown also slows down the crackpropagation rate. ${ }^{1,20-22}$

Since the 1980's, the tie-molecule (TM) fraction has been seen as one of the key parameters influencing the deformation and breakdown of craze fibrils in polyethylene. ${ }^{1,9,21,23}$ TMs form connections between adjacent crystalline lamellae (or, if the lamellae have been fractured, lamellar blocks) and, therefore, hold these crystalline parts together. ${ }^{1,9,21}$ Hence, it has been suggested in literature that TMs improve the connectivity between crystalline blocks in the craze fibrils, leading to a better stress distribution over the fibril and, therefore, to a decrease in deterioration rates for the fibril. ${ }^{1,2,9}$ A statistical model, relating the probability of forming a TM to both the molecular weight of a macromolecular chain and the polymer microstructure, has been proposed by Huang and Brown in the late 1980 's. ${ }^{1,21}$ This model assumes the formation of a tie-chain if the length of the Gaussian-distributed end-toend chain vector exceeds the bridging distance between two adjoining lamellae. ${ }^{1}$ Since the conception of this theory, various authors have used or adapted this approach to find a correlation between the crack-growth kinetics and the TM content. $^{24-26}$

Even though the theoretical approach of Huang and Brown has been used and adapted extensively, ${ }^{21,23-26}$ there are some aspects that have not been taken into account in the original equation. The most notable one is short-chain branching, in particular for bimodal copolymer grades, where the branches are placed on the high-molecular-weight chains. ${ }^{23,25,27}$ In this case, the effect of short-chain branches on the crack-growth kinetics is far greater than one would expect based on the variations in crystallinity and lamellar thickness. ${ }^{23,25,28}$ This has been explained by the inability of these short-chain branches to be incorporated into the crystalline lamellae, which stimulates the formation of TMs. ${ }^{23,25}$ Another notable aspect that was not considered in the original equation by Huang and Brown is the degree of connectivity provided by TMs of different lengths. ${ }^{1,21,28-30}$ According to the theory of Huang and Brown, each TM has the same effectiveness, regardless of how many crystalline lamella it connects. ${ }^{1,21,30}$ However, a more cohesive network should be formed by long chains in comparison to short(er) ones, as they connect a greater amount of lamellae. ${ }^{2,21,24,30}$ Similar observations were made by Zhou and Brown, ${ }^{28}$ who noted that the resistance to slow crack growth increased rapidly when a continuous network was formed between the crystalline domains. ${ }^{28,29}$

Even though the approach by Huang and Brown has been used extensively in literature, ${ }^{21,23-26}$ an in-depth investigation of the effect of other molecular parameters (such as the molecular moments) is still lacking. In the present study, we will focus on HDPE homopolymers and investigate the influence of the molecular moments [through the variation of the molecular weight distribution (MWD)] and the morphology (crystallinity and lamellar thickness) because these parameters are both theoretically relevant and easy to vary systematically.

In order to obtain a significantly large range of molecular moments, HDPE homopolymers have been synthesized with a systematic variation in both $M_{\mathrm{n}}$ and $M_{\mathrm{w}}$ (and, therefore, also in the polydispersity index) were used. In addition, a selection of these homopolymers were subjected to large variations in the cooling rate in order to obtain significant variations in lamellar thickness and crystallinity independent from the MWD. The correlation with these parameters will be compared to the correlation with the TM fraction derived from the formula of Huang and Brown. ${ }^{1,21}$ Variation in the number and placement of short-chain branches will be included in a subsequent publication because elimination of this variable would allow us to separate the effect of MWD and morphology from the branching content.

A practical problem that is encountered in studying slow crack-growth kinetics is that the required testing time may be extremely long. An effective manner to accelerate the crackgrowth assessment is making use of cyclic (fatigue) loading instead of static (creep) loading. The accelerating effect of cyclic loading on crack growth in polyethylene has been reported in a great number of publications. ${ }^{27,31-37}$ As mentioned above, a craze containing highly oriented craze fibrils is formed ahead of the crack tip during slow crack growth. $^{18-20,27,32,34,35,37}$ The rate of deformation and breakdown of these fibrils will control the observed crack-growth rate. $^{18-20,35}$ When a constant (static) load is applied, fibril deformation will mainly occur through the creep of the fibrils, predominantly caused by the disentanglement of the polymer chains within the fibrils. ${ }^{35}$ Upon the application of a cyclic load, the highly stretched craze fibrils will, depending on the load ratio, either bend or buckle during the unloading stage. $^{35,37}$ This will generate a highly localized stress on the segments of the fibrils where the curvature is the greatest, which is thought to accelerate failure in those segments of the fibril. $^{35,37}$ The acceleration of the failure strongly depends on the load ratio $R$, defined as $R=K_{\min } / K_{\max }$ with $K_{\min }$ and $K_{\max }$ 
being the minimum and maximum stress intensity factors during cyclic loading, respectively. ${ }^{31-33,35,37}$ It also depends on the loading frequency, which will influence the application frequency of the localized stress. ${ }^{34,35,37}$ Even though the fibrils are deformed in a different way during cyclic loading, it is typically assumed that chain disentanglement is still upheld as the main failure mechanism. ${ }^{35}$ This implies that crack-growth kinetics in the creep (static) load as well as in the fatigue (cyclic) load should be governed by the same molecular parameters. As a consequence, the ranking in creep-crackgrowth resistance is found to be identical to the ranking obtained from fatigue-crack growth. ${ }^{10,27,31-33,38}$ This assumption is also the basis for the ISO standard "ISO 18489:2015", which describes the use of fatigue in quality assessment of (polyethylene) pipegrades. ${ }^{10,31,38,39}$

\section{THEORETICAL BACKGROUND}

2.1. Theoretical Model of Huang and Brown. In the late 1980's, Huang and Brown proposed a statistical approach for the probability of TM formation. ${ }^{1,21}$ The basic assumption for their calculation was that a TM will only have a nonzero probability to form if the end-to-end distance of the molecule in the melt is greater than the bridging distance between adjoining lamellae. ${ }^{1,21}$ Given the lamellar thickness $L_{c}$ and the thickness of the amorphous interphase $L_{a}$, the bridging distance between adjoining lamellae was defined as $2 \times L_{c}+L_{a}$.

The formula for the root mean square end-to-end distance is given $b^{1,21}$

$$
\bar{r}=\sqrt{C_{\infty} n l^{2}}
$$

where $C_{\infty}$ is the characteristic ratio, $n$ is the number of monomers, and the covalent bond length $l=0.154 \mathrm{~nm} .{ }^{1,21}$ Because the number of bonds $n$ is related to the molecular weight of the polymer chain, $\bar{r}$ contains the molecular-weight dependence. The probability of a polymer chain having a given end-to-end distance $(p(r))$ is described by ${ }^{1,21}$

$$
p(r)=a r^{2} e^{-b^{2} r^{2}}
$$

where $a$ is a constant and $b^{2}$ is given by ${ }^{1,21}$

$$
b^{2}=\frac{2}{3 \bar{r}^{2}}
$$

Because a TM will only form if the end-to-end distance is greater than the distance between adjoining lamella $\left(2 \times L_{\mathrm{c}}+\right.$ $L_{\mathrm{a}}$ ), the probability of TM formation $P$ for a given $\bar{r}$ is as shown in $^{1,21}$

$$
P=\frac{1}{3} \frac{\int_{2 \mathrm{Lc}+\mathrm{La}}^{\infty} r^{2} e\left(-b^{2} r^{2}\right) \mathrm{d} r}{\int_{0}^{\infty} r^{2} e\left(-b^{2} r^{2}\right) \mathrm{d} r}
$$

According to Huang and Brown, the factor $1 / 3$ was introduced because two dimensions of the crystalline lamella are much larger than the distance between adjoining lamella. ${ }^{1,21}$ Because $b^{2}$ (and therefore $\bar{r}$ ) remains constant, the above formula for $P$ only applies for monodisperse systems. In order to take polydispersity into account, the number fraction $n(M)$ has to be introduced through ${ }^{1,21}$

$$
\bar{P}=\frac{\int_{0}^{\infty} n(M) P \mathrm{~d} M}{\int_{0}^{\infty} n(M) \mathrm{d} M}
$$

where $\bar{P}$ is the number fraction of all molecules that are TMs for the polydisperse polymer. ${ }^{1}$ Several alterations have been made to the theoretical formula over the years. ${ }^{21,24,25}$ One such alteration was made by Yeh and Runt, who used the radius of gyration $R_{\mathrm{g}}$ to calculate $b_{2}$ instead of $\bar{r}^{24}$ where the radius of gyration is given by

$$
R_{\mathrm{g}}=\sqrt{\frac{\bar{r}^{2}}{6}}
$$

In addition, the lower boundary for TM formation has also been subject to change in the past (it was $2 \times L_{\mathrm{c}}+2 \times L_{\mathrm{a}}$ in the original article), although the bridging distance between adjoining lamella $\left(2 \times L_{\mathrm{c}}+L_{\mathrm{a}}\right)$ is the most agreed upon boundary nowadays and is used in this study. ${ }^{21,25}$

\section{EXPERIMENTAL SECTION}

3.1. Materials. A broad variety of HDPEs, with a strong variation in both molecular moments and MWD, were investigated in this research. The most important material characteristics for these HDPEs are listed in Table 1 of appendix A. In this table, $M_{\mathrm{n}}, M_{\mathrm{w}}$, and

\section{Table 1. CT Specimen Dimensions}

\begin{tabular}{lccc} 
& small & medium & large \\
$B[\mathrm{~mm}]$ & 2 & 6 & 12 \\
$W[\mathrm{~mm}]$ & 16 & 32 & 64 \\
$H[\mathrm{~mm}]$ & 19.2 & 38.5 & 77 \\
\hline
\end{tabular}

$M_{\mathrm{z}}$ are the number-, weight-, and $\mathrm{Z}$-average molecular weights, respectively. $L_{\mathrm{c}}$ and $L_{\mathrm{a}}$ are, respectively, the lamellar thickness and the thickness of the amorphous layer, while the number-based TM fraction is derived by eq 5 . The test temperature is denoted by $T$. The HDPEs have been named through a system that concentrates on the molecular aspects of the tested grades. Within the code $Q P E-X-Y-Z, Q$ stands for the incorporated molecular architecture $(H$ for the homopolymer), while $X, Y$, and $Z$ indicate, respectively, the number-, weight-, and z-average molar mass of the grade in $\mathrm{kg} / \mathrm{mol}$. Hence, a grade with the code HPE-15-88-450 is a homopolymer grade with an $M_{\mathrm{n}}$ of $15 \times 10^{3}$, an $M_{\mathrm{w}}$ of $88 \times 10^{3}$, and an $M_{\mathrm{z}}$ of $450 \times 10^{3}$.

3.2. Size Exclusion Chromatography. The MWDs were determined through size-exclusion chromatography performed at SABIC using universal calibration. The measurements were performed on a Polymer Laboratories PL-GPC220 equipped with a Polymer Laboratories PL BV-400 viscometer, a refractive index detector, and a Polymer Char IR5 infrared detector. Three Polymer Laboratories $13 \mu \mathrm{m}$ PLgel Olexis columns, $300 \times 7.5 \mathrm{~mm}$, were used as the stationary phase, while trichlorobenzene was used as the mobile phase. The calibration of the PE molar mass was performed with linear PE standards in the range of $0.5-2800 \mathrm{~kg} / \mathrm{mole}$. Data obtained from measurements within one run showed average deviations of 10 , 8 , and $11 \%$ for $M_{n}, M_{w}$, and $M_{z}$, respectively, between the different measurements (confidence interval: 95\%). The deviation between measurements of different runs were 15,10 , and $13 \%$ for $M_{\mathrm{n}}, M_{\mathrm{w}}$, and $M_{z}$, respectively (confidence interval: $95 \%$ ).

3.3. Small- and Wide-Angle X-ray Measurements. X-ray measurements have been performed on a Bruker D8 DISCOVER system, equipped with a $\mathrm{Cu}$-tube and Montel primary optics to provide a highly parallel beam, collimated at $0.2 \mathrm{~mm}$ spot focus size. $\mathrm{Cu} \mathrm{K} \alpha$ radiation with a wavelength of $1.54 \AA$ was used to perform the measurements. For wide-angle X-ray diffraction (WAXD) measurements, an Eiger2R $500 \mathrm{~K}$ detector with a pixel size of $75 \times 75 \mu \mathrm{m}^{2}$ was placed at a sample to detector distance of $33.4 \mathrm{~mm}$ and an acquisition time of $120 \mathrm{~s}$ was maintained. For small-angle X-ray scattering (SAXS) measurements, a sample to detector distance of $479.1 \mathrm{~mm}$ and an acquisition time of $900 \mathrm{~s}$ were used. The patterns obtained for both WAXD and SAXS were background subtracted and radially integrated to obtain intensity versus scattering angle $2 \theta$ or 
scattering vector $q$ for WAXD and SAXS, respectively, where the scattering vector $q$ was calculated from $2 \theta$ using Bragg's law ${ }^{40}$

$$
q=\frac{4 \pi}{\lambda} \sin (\theta)
$$

where $\lambda$ is the wavelength of the radiation and $\theta$ is half of the scattering angle $2 \theta$. The crystallinity of the polyethylene samples was calculated from the WAXD measurements by integrating the baseline corrected intensity as a function of $2 \theta$ and subtracting the integrated intensity of the amorphous halo to obtain the integrated intensity of the crystalline fraction. The weight fraction crystallinity $\chi_{\mathrm{w}}$ was obtained by using the following formula: ${ }^{40}$

$$
\chi_{\mathrm{w}}=\frac{C_{\mathrm{c}}}{C_{\mathrm{tot}}}=\frac{C_{\mathrm{tot}}-C_{\mathrm{a}}}{C_{\mathrm{tot}}}
$$

where $C_{\text {tot }}$ is the total integrated intensity, $C_{c}$ is the integrated intensity of the crystalline fraction, and $C_{a}$ is the integrated intensity of the amorphous halo. ${ }^{40}$ The long period was determined by finding the scattering vector $q$ for the maximum of the Lorentz-corrected intensity $\left(I q^{2}\right)^{40,41}$ using the following equation

$$
L_{\mathrm{p}}=\frac{2 \pi}{q_{\max }}
$$

where $q_{\max }$ is the scattering vector at the maximum of $I q^{2}$. The lamellar thickness was calculated from the long period and the volume fraction crystallinity through the following formula ${ }^{40}$

$$
L_{\mathrm{c}}=\chi_{\mathrm{v}} \times L_{\mathrm{p}}
$$

Here, $\chi_{\mathrm{v}}$ is the volume fraction crystallinity, which is calculated from the weight fraction crystallinity through the following formula ${ }^{40}$

$$
\chi_{\mathrm{v}}=\frac{\frac{\chi_{\mathrm{w}}}{\rho_{\mathrm{c}}}}{\frac{\chi_{\mathrm{w}}}{\rho_{\mathrm{c}}}+\frac{\left(1-\chi_{\mathrm{w}}\right)}{\rho_{\mathrm{a}}}}
$$

where $\rho_{\mathrm{c}}$ and $\rho_{\mathrm{a}}$ are the densities of the crystalline and amorphous phases, respectively.

3.4. Sample Preparation. The crack-growth kinetics were studied using compact-tension (CT) specimens with dimensions according to ASTM standard E647. ${ }^{42}$ To produce the precursor samples for the $6 \mathrm{~mm}$ CT specimens, two different methods were applied. For high-molecular-weight materials, CT-specimen precursor samples were prepared by compression moulding plaques in an $85 \times$ $42 \times 8 \mathrm{~mm}^{3}$ mould at $200{ }^{\circ} \mathrm{C}$. The material was first allowed to melt without external pressure, before cycling between 0 and $20 \mathrm{kN}$ several times in order to degas the material. The pressure was increased in a stepwise fashion to $100 \mathrm{kN}$, where the sample was compression moulded for $3 \mathrm{~min}$. Due to constrained shrinking at the edges of the mould, these precursor samples were thinner in the center than they were at the edges of the sample.

For low-molecular-weight materials, plaques were compression moulded in a $100 \times 100 \times 10 \mathrm{~mm}^{3}$ picture frame mould, due to the large amount of bubble formation and warping that occurred when the first method was used for these materials. The samples were compression moulded at $160{ }^{\circ} \mathrm{C}$ at $15 \mathrm{kN}$ to prevent significant overflow from the closed mould. The material was allowed to completely melt before the top block was placed into the mould. The samples produced by both methods were cooled at a controlled cooling rate of $10{ }^{\circ} \mathrm{C} / \mathrm{min}$ and were checked afterward for the presence of voids or bubbles.

The precursor samples were then machined into CT specimens with a width of $40 \mathrm{~mm}$ and a height of $38 \mathrm{~mm}$. Due to slight warpage, the precursors were machined into flat plates, which were consistently between 5 and $6 \mathrm{~mm}$ thick. The exact thickness $B$ (see Figure 1) was measured with $0.01 \mathrm{~mm}$ precision for each sample. The CT-specimen dimension $W$ (see Figure 1) was $32 \mathrm{~mm}$. The machined CT specimens were provided with a precrack by tapping in a razor blade with a pendulum set at a predefined height. A fresh razor blade was used for each specimen. The length of the precrack, as well as the

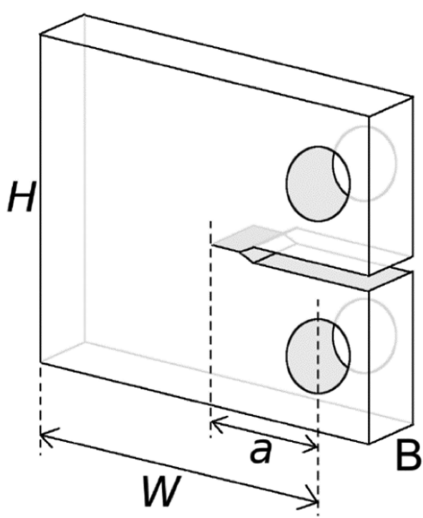

Figure 1. Schematic representation of a CT specimen.

distance between the center of the pinholes and the tip of the sawed notch, were measured with an optical microscope at $3.15 \times$ and $0.41 \times$ magnification, respectively. The length of the tapped notch was measured from both sides with a precision of $0.01 \mathrm{~mm}$ and the average of the two values was taken. This yielded precracks with a typical length of $1.25 \mathrm{~mm}$. The distance between the center of the pinholes and the tip of the sawed notch was also measured with 0.01 $\mathrm{mm}$ precision and was typically around $7 \mathrm{~mm}$, making the combined initial crack length $a$ nominally $8.25 \mathrm{~mm}$.

The plaques used for $2 \mathrm{~mm}$ thick CT specimens were produced for four homopolymer grades (HPE-8.4-51-230, HPE-12-75-350, HPE4.4-197-1790, and HPE-6.5-207-1990) in a $160 \times 160 \times 3 \mathrm{~mm}^{3}$ mould at $200{ }^{\circ} \mathrm{C}$. The compression moulding procedure was largely the same as the procedure used for the $6 \mathrm{~mm}$ thick samples. However, three different cooling procedures were used in order to investigate the effect of the cooling rate on the selected grades. The first cooling procedure was controlled cooling at $10{ }^{\circ} \mathrm{C} / \mathrm{min}$, which was used as a reference for comparison with the $6 \mathrm{~mm}$ thick samples. The other two cooling procedures were, respectively, overnight cooling after switching of the press (approximately $0.5^{\circ} \mathrm{C} / \mathrm{min}$ ) and cooling in a water cooled press (approximately $50{ }^{\circ} \mathrm{C} / \mathrm{min}$ ). The plaques were machined into CT specimens with a width of $20 \mathrm{~mm}$ and a height of $19 \mathrm{~mm}$. The thickness B of the specimens was consistently between 1.9 and $2 \mathrm{~mm}$ and was, once more, measured with $0.01 \mathrm{~mm}$ precision for each sample. The CT-specimen dimension $W$ was $16 \mathrm{~mm}$. The precrack of the $2 \mathrm{~mm}$ thick specimens was created using the same procedure used for the $6 \mathrm{~mm}$ thick samples. The length of the precrack and sawed notch were determined with an optical microscope using the same setting as for the $6 \mathrm{~mm}$ thick samples. Typical lengths for the precracks and sawed notches were 1 and 3.5 $\mathrm{mm}$, respectively, resulting in an average initial crack length $a$ of 4.5 $\mathrm{mm}$.

The plaques used for the $12 \mathrm{~mm}$ thick specimens were also produced using the above-mentioned procedure for the 2 and $6 \mathrm{~mm}$ specimens. The applied cooling rate was $10{ }^{\circ} \mathrm{C} / \mathrm{min}$. The thickness $B$ was between 12 and $12.5 \mathrm{~mm}$ and was determined with $0.01 \mathrm{~mm}$ precision for each sample, while $W$ was $64 \mathrm{~mm}$. The precrack was made with the same procedure as the one used for the other two thicknesses. The average length of the sawed notch was typically 13.5 $\mathrm{mm}$, while the average length of the precrack was approximately 1.5 $\mathrm{mm}$, resulting in a combined initial crack length $a$ of $15 \mathrm{~mm}$.

3.5. Specimen Testing. The CT specimens were tested under cyclic (fatigue) loading on mechanical testing machines from various suppliers (Instron, Zwick, MTS), which were capable of accurately supplying the required load pattern. A sinusoidal load pattern was applied on the sample under cyclic loading in order to increase the crack-growth rate and accelerate the measurements. ${ }^{27,31-37,43}$ Measurements were performed at temperatures ranging from room temperature $\left(23{ }^{\circ} \mathrm{C}\right)$ to $92{ }^{\circ} \mathrm{C}$. Unless mentioned otherwise, the frequency of the sinusoidal load was $5 \mathrm{~Hz}$. The stability of the load pattern was checked afterward for several samples, and it was seen that the load pattern conformed to the shape of a perfect sine with a 


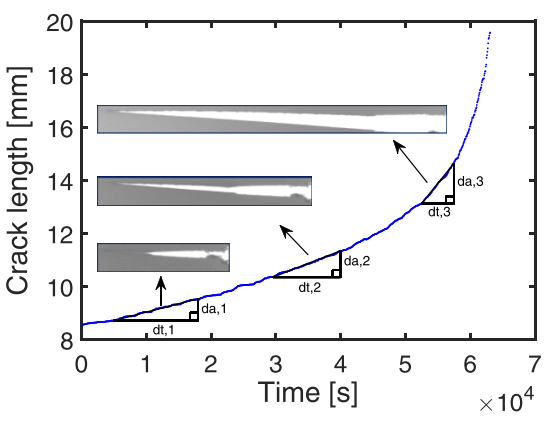

(a)

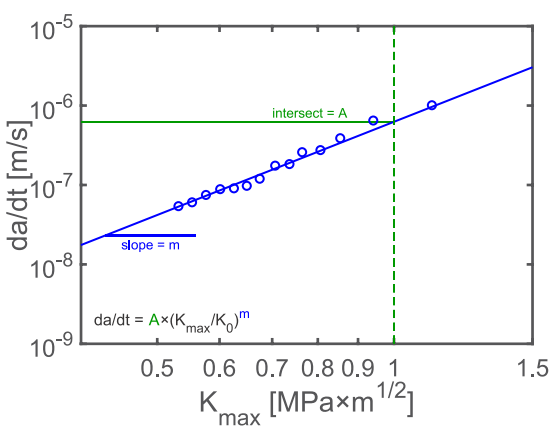

(b)

Figure 2. Log-log plot of crack length versus time (a) and crack-growth rate versus stress intensity factor (b). The blue markers are data points. The blue line in (b) is the optimized fit of the Paris-Erdogan law, eq 13.

coefficient of determination $\left(R^{2}\right.$ value $)>0.995$ for most of the test, which only deviated from this value close to failure. The samples were tested at a load ratio of $R=0.1$, where $R=K_{\min } / K_{\max }$. For each material, at least two measurements were performed.

A macrolens (Bresser macrolens $60 \mathrm{~mm} \mathrm{~F} / 2.8$ ) with a manual zoom and a maximum magnification of $2 \times$ was used together with a high speed, monochrome camera (Pixelink PL-D725MU) to track the growth of the crack front. The pixel to $\mathrm{mm}$ ratio (expressed in $\mathrm{mm} /$ pixel) was determined through the use of a calibration sample engraved with a grid of $3 \times 3 \mathrm{~mm}^{2}$ squares. The engraving was performed with a nanoindenter to ensure high precision of the created grid. A field of view of around $10 \mathrm{~mm}$ was used for the $6 \mathrm{~mm}$ thick samples. This field of view was reduced to approximately $7 \mathrm{~mm}$ for the $2 \mathrm{~mm}$ thick samples. To determine the crack opening at maximum load, a movie of five consecutive cycles was made at a set time interval and the frames in which the crack was at maximum opening were isolated and used for the determination of the position of the crack front. The time interval was adjusted based on the duration of the measurement. The amount of frames per second (fps) captured by the camera depended on the frequency used in the measurement but was taken such that there were at least 20 frames per cycle. Hence, a frame rate of $100 \mathrm{fps}$ was used at a frequency of $5 \mathrm{~Hz}$. From the difference between the position of the crack front and the position of the end of the precrack, the crack length (in number of pixels) was determined at maximum opening as a function of time (calculated from the time interval). This crack length was, subsequently, converted from number of pixels to $\mathrm{mm}$ using the pixel to $\mathrm{mm}$ ratio and added to the length of the precrack and sawed notch, which were determined earlier, see Section 3.4. This yielded the evolution of crack length (in $\mathrm{mm}$ ) as a function of time, as presented in Figure 2a.

3.6. Analysis of the Crack Length versus Time Data. In order to obtain the crack propagation rate as a function of the stress intensity factor, the crack propagation rate had to be determined from the crack length versus time curves. This was achieved by determining the (linear) slope over a number of crack length versus time data points at various intervals of the curve through linear interpolation, as shown in Figure 2a. The amount of data points, taken for linear interpolation for a given section, was varied in such a way that more data points were taken at the start of the curve (where the crack propagation rate was low), in order to reduce the effect of pixelation and measurement noise on the crack propagation rate. Less points were taken at the end of the curve (where the crack propagation rate was high), due to the greater curvature and higher nonlinearity of the curve at that point. The data points at the initial stage of the measurement, where the crack had to move through the initial plastic zone caused by the tapping of the crack, were discarded because they did not represent stable slow crack growth. The interpolated intervals were taken in such a way that the coefficient of determination $\left(R^{2}\right.$ value) was generally above 0.95 and the $95 \%$ confidence interval was, in general, less than $\pm 10 \%$ of the determined crack propagation rate at that interval. The stress intensity factor $K_{\max }$ was calculated, for each crack propagation rate, from the value of the crack length in the middle of the range through the following equation

$$
\begin{aligned}
K_{\max }= & \frac{F_{\max }}{B \sqrt{W}} \frac{2+\alpha / W}{(1-\alpha / W)^{3 / 2}}\left[0.866+4.64(\alpha / W)-13.32(\alpha / W)^{2}\right. \\
& \left.+14.72(\alpha / W)^{3}-5.60(\alpha / W)^{4}\right]
\end{aligned}
$$

where $F_{\max }$ is the maximum applied load, $B$ is the thickness of the specimen, $W$ is the distance between the center of the pinholes and the end of the specimen, and $\alpha$ is the length of the crack measured from the center of the pinholes. In this research, both the stress intensity factor and the crack length are determined at the maximum load, which is indicated by the subscript of the stress intensity factor $K_{\max }$. The crack propagation rate $\mathrm{d} a / \mathrm{d} t$ was plotted against $K_{\max }$ in a double logarithmic plot, as shown in Figure $2 b$. The Paris-Erdogan law was subsequently fitted to the data in order to determine the Paris-Erdogan exponent $m$ and prefactor $A$

$$
\frac{\mathrm{d} a}{\mathrm{~d} t}=A *\left(K_{\max } / K_{0}\right)^{m}
$$

where $\mathrm{K}_{0}=1 \mathrm{MPa} \sqrt{\mathrm{m}}$. Within the double-logarithmic plot, the slope of the fitted line is equal to the Paris-Erdogan exponent $m$, while the (predicted) crack propagation rate at $K_{\max }=1 \mathrm{MPa} \sqrt{ } \mathrm{m}$ is equal to the Paris-Erdogan prefactor $A$.

\section{RESULTS AND DISCUSSION}

\subsection{Influence of CT-Specimen Size on Crack Growth}

Kinetics. As mentioned in Section 3.4, mid-sized CT specimens with a thickness ranging between 5 and $6 \mathrm{~mm}$ were used in the majority of the experimental work shown in this study. However, in order to verify if linear elastic fracture mechanics applied to the specimens of this thickness, specimens of other thicknesses have been tested as well. Besides the mid-sized samples (listed as $6 \mathrm{~mm}$ ), samples with nominal thicknesses of 2 and $12 \mathrm{~mm}$ were used to obtain a relatively large thickness range. The $2 \mathrm{~mm}$ samples had the additional benefit that they could be used to study the effect of processing conditions (or more specifically, cooling rate) on the crack-growth kinetics. In order to make a proper comparison between $\mathrm{CT}$ specimens of varying thicknesses, controlled cooling at $10{ }^{\circ} \mathrm{C}$ was used. The results of the comparison are shown in Figure 3 for HPE-6.5-207-1990. While some spread is still visible between the measurements performed with CT specimens of different thicknesses, it can be seen that all the measurements approximately fall on one line and that a significant overlap is shown between the measurements on 2 and $6 \mathrm{~mm}$ thick samples. This indicates that the effect of sample thickness is relatively small. In addition, when the deviation between the measurements at different thicknesses is compared to the variation observed between different measurements at one thickness, as well as the 


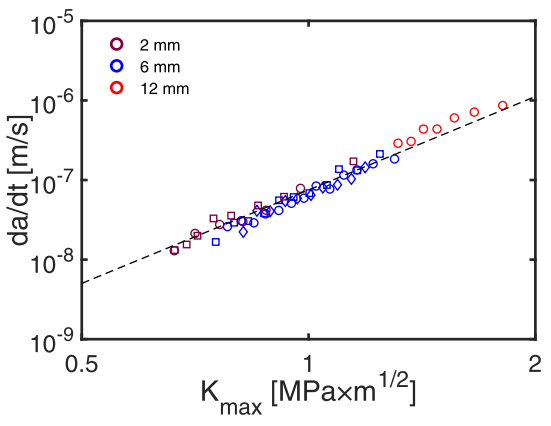

Figure 3. Log-log plot of crack-growth rate $(\mathrm{d} a / \mathrm{d} t)$ versus stress intensity factor shown for different sample thicknesses of HPE-6.5207-1990. The purple, blue, and red markers correspond to samples with thicknesses of 2,6 , and $12 \mathrm{~mm}$, respectively. The black dashed line is a guide to the eye. The slope of the line is equal to 3.9.

experimental error on these measurements, it can be seen that the variations between different thicknesses fall within experimental error. Hence, it can be concluded that the crack-growth kinetics show no significant dependence on sample thickness. Therefore, it can be postulated that linear elastic fracture mechanics applies to the $6 \mathrm{~mm}$ thick samples.

4.2. Crack-Growth Kinetics Curves. As mentioned in Section 3.6, the Paris-Erdogan law was used to describe the crack-growth kinetics curves of the HDPE grades, and the Paris-Erdogan law parameters $A$ and $m$ were determined through optimized two parameter fits of the data. Upon the performance of an optimized two parameter fit for each homopolymer grade, the prefactor $A$ varies considerably (nearly 3 orders of magnitude), while the exponent $m$ fluctuates within the range of 3.3 to 4.5 , which is comparable to the variation observed in literature for the exponent $m$ of polyethylene. $^{12,22,31-33,44}$ However, as shown by literature, a single, theoretical value $(m=4)$ can be derived for the exponent $m$ from the Dugdale model. ${ }^{11,12,22,32,33}$ Hence, it would be probable that all of the HDPE grades used in this study can be described with a single Paris-Erdogan exponent $m$. Therefore, it was decided to collectively fit all of the Paris law curves with the same exponent $m$, which can be seen in Figure $4 a, b$. A weighted optimization procedure over all the obtained crack propagation rate versus $K_{\max }$ data revealed an optimal Paris-Erdogan exponent $m$ of 3.9, which lies close to the theoretical value obtained from the Dugdale model. ${ }^{11,12,22,32,33}$ Because the curves in Figure 4a,b have the same slope (exponent $m$ ), the observed fatigue crack-growth kinetics depend solely on the Paris-Erdogan prefactor $A$. This implies that the prefactor $A$ is the governing parameter for the crack-growth kinetics.

4.3. Influence of Molecular and Morphological Parameters on Fatigue Crack-Growth Kinetics. As mentioned in the previous section, the Paris-Erdogan prefactor $A$ is the parameter that governs the fatigue crackgrowth kinetics of polyethylene. Furthermore, this implies that any material parameter governing the crack-growth kinetics will be related to the prefactor $A$. Therefore, the prefactor $A$, found for $m=3.9$, was chosen as the parameter that best represents the resistance of HDPE grades against fatigue crack growth. In the following sections, this prefactor $A$ will be correlated with the parameters mentioned in the introduction in order to identify which parameter has the strongest influence on the crack-growth kinetics.

4.3.1. Correlation with the TM Fraction. Initially, the prefactor $A$ was correlated with the benchmark used in most literature studies: the TM fraction as derived by Huang and Brown, ${ }^{1,21}$ which is shown in Figure 5. As can be seen from

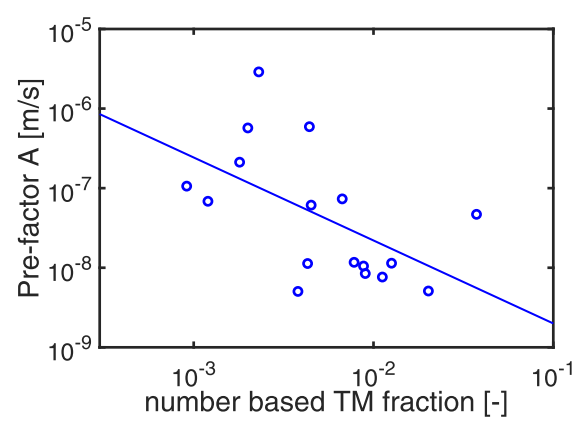

Figure 5. Log-log plot of prefactor A versus the number-based TM fraction. The markers are data points, while the solid line is the optimized power-law fit of the data.

Figure 5, the TM fraction shows a rather poor correlation with prefactor $A$, which is reflected by the coefficient of determination $\left(R^{2}\right.$-value) seen for the optimal power-law fit $\left(R^{2}=0.303\right)$. The weak correlation between the prefactor $A$ and the TM fraction is most likely related to the omission of the influence of the trapped entanglements on the stability of the craze fibril. As first mentioned by Yeh and Runt, the number of entangled loops is considerably greater than the number of TMs. ${ }^{24,45}$ Because an entangled loop can contain

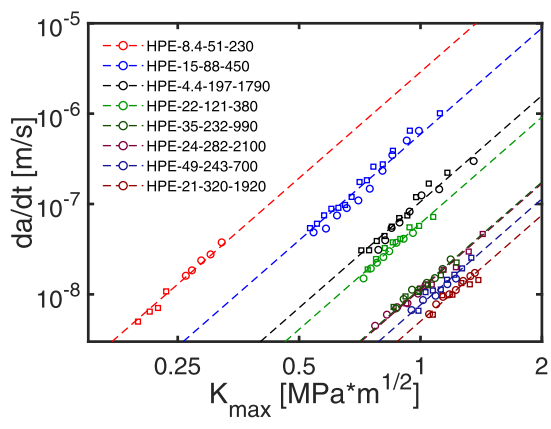

(a)

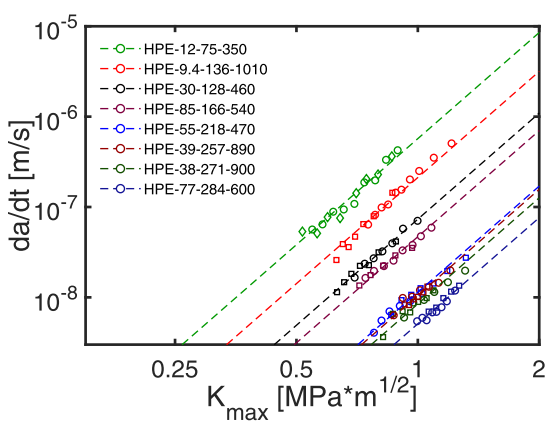

(b)

Figure 4. $\log -\log$ plot of crack-growth rate $(\mathrm{d} a / \mathrm{d} t)$ versus stress intensity factor for the optimized single parameter fits of the Paris-Erdogan law with a constant Paris-Erdogan exponent of $m=3.9$. The markers are data points, while the dashed lines are the optimized fits. Due to the large quantity of data, the curves are split over two different graphs: curves 1-8 in (a) and curves 9-16 (b). 
more than one trapped entanglement, it will greatly improve the cohesion of both the entanglement network and the network of lamellar blocks within the fibril. ${ }^{28,29}$ Therefore, including the contribution of the entangled loops would, most likely, improve the correlation. However, while adapting the Huang and Brown equation to include entangled loops is possible, ${ }^{24}$ it makes the formula significantly more complex.

A mathematically simpler alternative would be to use the average number of effective physical cross-links per chain, $\bar{N}_{\mathrm{c}}{ }^{2}$ The advantage of this parameter is that it intrinsically shows the degree of cohesion within the molecular network, therefore containing the contributions of both TMs and entangled loops. Because only the effective physical cross-links are taken into account, this parameter, similar to the TM fraction by Huang and Brown, excludes short chains that form ineffective crosslinks. ${ }^{2}$ Additionally, this parameter requires the same input data as the formula of Huang and Brown (MWD, lamellar thickness, and thickness of the amorphous layer); ${ }^{2}$ hence, $\bar{N}_{\mathrm{c}}$ can be easily compared to the TM fraction in terms of effectiveness. $\bar{N}_{c}$ is proportional to the number-average molecular weight corrected for low-molecular-weight chains $\left(\phi \bar{M}_{\mathrm{n}}{ }^{*}\right)$, which can be calculated from the afore-mentioned parameters (see appendix B for the mathematical equations). ${ }^{2}$

The correlation between the prefactor $A$ and $\phi M_{\mathrm{n}}^{*}$ is shown in Figure 6. While a definite improvement is seen for the

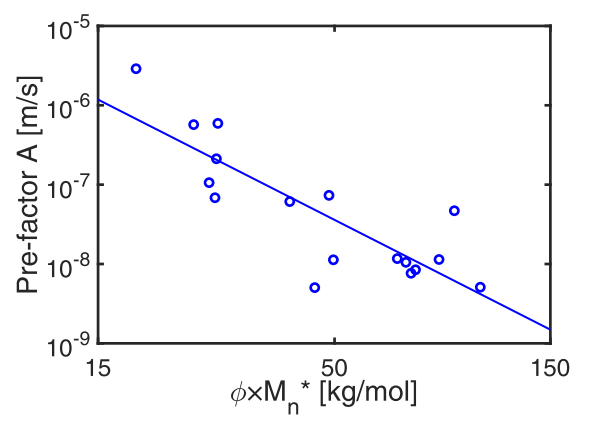

Figure 6. Log-log plot of the prefactor A versus the corrected $M_{\mathrm{n}}\left(\phi M_{\mathrm{n}}^{*}\right)$. The markers are data points, while the solid line is the optimized power-law fit of the data.

correlation when compared to the TM fraction, the spread over the data for $\phi M_{\mathrm{n}}^{*}$ is still considerable, which is reflected by the relatively low $R^{2}$-value $\left(R^{2}=0.701\right)$. Upon closer inspection, it is seen that the width of the MWD in particular has a greater effect on this parameter than expected because HDPE grades with either very narrow or very broad MWD distributions are among the strongest outliers. More specifically, the prefactor $A$ for the HDPE grade with the broadest MWD was greatly overestimated, while it was greatly underestimated for the most narrow HDPE grade. The observations shown above indicate that, even though the inclusion of entangled loops improves the correlation (compare Figures 5 and 6 ), $\phi M_{n}^{*}$ also lacks a convincing correlation with the crack-growth kinetics. In this case, however, the molecular parameter included the contribution of all stress-transmitting molecules (TMs, entangled loops) on the stability of the fibril, instead of solely the contribution of the TMs. This would imply that the fraction of stresstransmitting molecules might not be the governing the parameter for the fatigue crack-growth kinetics. Additionally, because $\phi M_{n}^{*}$ should theoretically correlate with the strength of the molecular network, ${ }^{2}$ the observations indicate that the strength of the molecular network alone does not determine the resistance to slow crack growth. Therefore, a different molecular parameter has to be found, which incorporates, but is not limited to, the molecular network.

4.3.2. Correlation with Molecular Moments. As shown in the previous section, neither the TM fraction nor the average number of effective physical cross-links per chain $\left(\bar{N}_{c}\right)$ show a convincing correlation with prefactor $A$ (and, therefore, the crack-growth kinetics). However, as can be seen from the curves in Section 4.3, the prefactor $A$ is strongly influenced by the MWD or, more specifically, by the molecular moments. Hence, in order to make the first step toward uncovering which molecular parameter governs the crack-growth kinetics, the prefactor $A$ was correlated to the most commonly used molecular moments: $M_{\mathrm{n}}, M_{\mathrm{w}}$, and $M_{\mathrm{z}}$, as shown in a-c of Figure 7, respectively. As can be seen from these figures, the prefactor $A$ shows the best power-law correlation with $M_{\mathrm{w}}$ (coefficient of determination, $R^{2}=0.899$ ), while a poor correlation is seen with both $M_{\mathrm{n}}$ and $M_{\mathrm{z}}\left(R^{2}\right.$ equal to 0.438 and 0.247 , respectively). Although it is known for both polyethylene $^{1,21,23,46,47}$ and other polymeric materials ${ }^{47-49}$ that crack propagation decelerates with increasing molecular weight, the effect of MWD on crack-growth dynamics has received much less attention. Specifically, the good correlation of the prefactor $A$ with the weight-average molecular weight has, to our knowledge, not been observed before. For oriented polyethylene monofilaments (fibers), it has been shown by Wilding and Ward that an increase in the molecular weight has a decelerating effect on the creep rate, which was attributed to the increasing contribution of the entanglements on the resistance of the molecular network to chain slip. ${ }^{50-52}$ Because craze fibrils are extended to large strain values within the craze zone, a similar effect could be expected for these craze fibrils. This would suggest that the crack-growth kinetics for HDPE homopolymers could be governed by a chain slip within the craze fibrils. This will be investigated further in the following sections.

4.4. MWD Dependence: Parameter Optimization. As can be seen in Section 4.3.2, $M_{\mathrm{w}}$ yielded an improved correlation over both the TM fraction and the average number of effective physical cross-links per chain. Still, several important observations can be made from the results in Section 4.3.1. First of all, a marked improvement can be observed when only chains contributing to the molecular network are taken into account (compare the correlation of prefactor $A$ with $\phi M_{n}^{*}$ to the correlation with $M_{n}$ ). Second of all, it was already mentioned in Section 4.3.1 that the width of the MWD also has a significant effect on the crack-growth kinetics, in particular at (extremely) high or low polydispersity. This can clearly be observed when several HDPEs are chosen with (approximately) the same $M_{\mathrm{w}}$ but different polydispersity indexes (see Figure 8). To investigate the effect of polydispersity in more detail, a parameter optimization was performed, using $M_{\mathrm{n}}, M_{\mathrm{w}}$, and $M_{\mathrm{z}}$ as the input variables.

4.4.1. Parameter Optimization: Molecular Moments. In an ordinary parameter optimization, each input variable is presented as independent with regard to the other input variables, preferably in a linearized manner to allow for linear parameter optimization. Because the correlation takes place on a $\log -\log$ scale, a multivariable power law would be the ideal starting point

$$
A / A_{0}=C_{0} M_{n}^{a} M_{w}^{b} M_{z}^{c}
$$




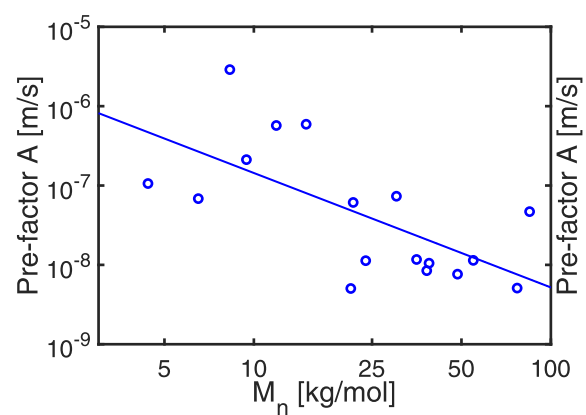

(a)

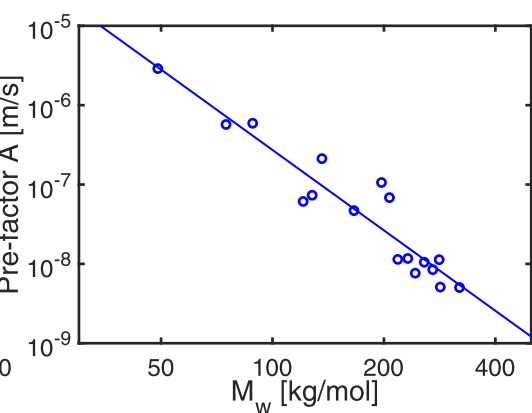

(b)

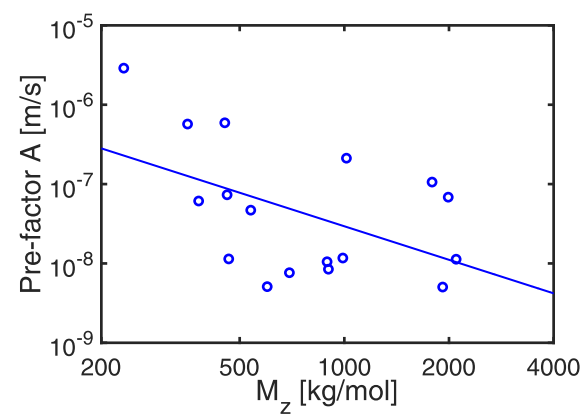

(c)

Figure 7. $\log -\log$ plots of the prefactor A versus (a) $M_{\mathrm{n}}$, (b) $M_{\mathrm{w}}$, and (c) $M_{\mathrm{z}}$. The markers are data points, while the solid lines are optimized power-law fits of the data.

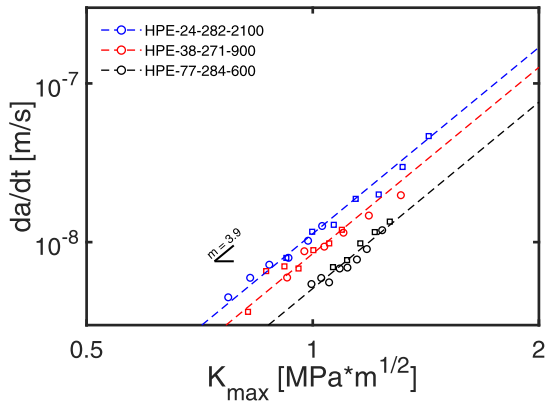

Figure 8. Log-log plot of crack-growth rate $(\mathrm{d} a / \mathrm{d} t)$ versus stress intensity factor for three HDPEs with approximately the same $M_{\mathrm{w}}$ $(282,271$, and $284 \mathrm{~kg} / \mathrm{mol}$, respectively) but different polydispersity indexes (11.8, 7.1, and 3.7, respectively).

here $A_{0}=1 \mathrm{~m} / \mathrm{s}, C_{0}$ is a dimensionless constant, and $a, b$, and $c$ are the power-law exponents. Because the equation is written as a power law, it can be linearized by taking the logarithm (in what follows, log denotes the logarithm with respect to base 10: $\left.\log (x)=\log _{10}(x)\right)$

$$
\begin{aligned}
\log \left(A / A_{0}\right)= & \log \left(C_{0}\right)+a \log \left(M_{\mathrm{n}}\right)+b \log \left(M_{\mathrm{w}}\right) \\
& +c \log \left(M_{\mathrm{z}}\right)
\end{aligned}
$$

A multilinear fit of eq 15 to the data presented in Table 1 was performed and resulted in parameter estimations shown in Table 2. From the values in this table, it follows that the prefactor $A$ correlates well with $M_{\mathrm{w}}$ and has a weak correlation with $M_{\mathrm{z}}$. Notably, it shows that adding the variable $M_{\mathrm{n}}$ does not improve the correlation, as the value $a=0$ (no correlation improvement with $M_{\mathrm{n}}$ ) lies within the confidence interval.
Table 2. Multilinear Fit Parameters of eq 15 to the Data in Table 1

$\begin{array}{lccc} & \text { estimate } & \text { standard error } & 95 \% \text { confidence interval } \\ \log C_{0} & -0.6 & 0.4 & \{-1.6,0.3\} \\ A & -0.2 & 0.2 & \{-0.7,0.3\} \\ B & -4.0 & 0.5 & \{-5.2,-2.9\} \\ C & 0.9 & 0.4 & \{0.0,1.7\}\end{array}$

It thus appears that the prefactor $A$ is mostly governed by $M_{\mathrm{w}}$ and weakly depends on $M_{\mathrm{z}}$ as

$$
\log (A)=\log \left(C_{1}\right)+p \log \left(M_{\mathrm{w}}\right)+q \log \left(M_{\mathrm{z}}\right)
$$

with the proportionality constant $C_{1}$ and the new power-law coefficients $p$ and $q$. The value estimates of $C_{1}, p$, and $q$ that follow from a multilinear fit of the data in Table 1 to eq 16 are shown in Table 3.

Table 3. Multilinear Fit Parameters of eq 16 to the Data in Table 1

\begin{tabular}{lccc} 
& estimate & standard error & $95 \%$ confidence interval \\
$\log C_{1}$ & -0.8 & 0.4 & $\{-1.6,0.0\}$ \\
$P$ & -4.4 & 0.2 & $\{-4.9,-3.9\}$ \\
$Q$ & 1.1 & 0.2 & $\{0.8,1.5\}$ \\
\hline
\end{tabular}

The new fit using only $M_{\mathrm{w}}$ and $M_{\mathrm{z}}$ has a higher adjusted $R^{2}$, $\bar{R}^{2}=0.970823$, compared to the fit using $M_{\mathrm{n}}, M_{\mathrm{w}}$, and $M_{\mathrm{z}}\left(\bar{R}^{2}=\right.$ $0.969917)$, again indicating that including $M_{\mathrm{n}}$ as a variable does not improve the description of the molecular weight dependence of prefactor $A$. Here, the adjusted coefficient of determination $\bar{R}^{2}$ is a measure of the quality of the fit that 
provides a penalty to $R^{2}$ for each regression coefficient added to the model. ${ }^{53}$

Using the parameters in Table 3, the power-law dependence of $A / A_{0}$ can be expressed as follows

$$
\begin{aligned}
A / A_{0} & =C_{1} M_{\mathrm{w}}{ }^{-4.4} M_{\mathrm{z}}^{1.1}=C_{1}\left(M_{\mathrm{w}}\left(\frac{M_{\mathrm{z}}}{M_{\mathrm{w}}}\right)^{-0.35}\right)^{-3.3} \\
& =C_{1}\left(M_{\mathrm{w}}\left(\frac{M_{\mathrm{z}}}{M_{\mathrm{w}}}\right)^{r}\right)^{p}
\end{aligned}
$$

the terms within the outermost brackets of the last equality in eq 17 can be seen as a width-corrected $M_{w}$, where the correction term is provided by the ratio $\left(M_{\mathrm{z}} / M_{\mathrm{w}}\right)^{r}$ with $r=$ -0.35 .

The results of the parameter optimization are shown in Figure 9. The exponent $p$ is equal to $p=-3.3$, which is close to

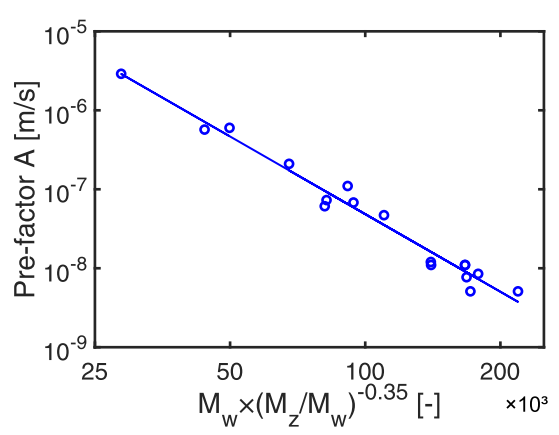

Figure 9. $\log -\log$ plot of the Paris-Erdogan prefactor $A$ versus the width-corrected $M_{\mathrm{w}}: M_{\mathrm{w}}\left(M_{\mathrm{z}} / M_{\mathrm{w}}\right)^{-0.35}$. The markers are data points, while the solid line is the multilinear power-law fit.

the inverse of the universal power-law dependence of the zeroshear viscosity $\eta_{0}$ on $M_{\mathrm{w}}\left(\eta_{0} \propto M_{\mathrm{w}}^{3.4}\right)$, that is observed for many polymer melts. ${ }^{54-56}$ This seems to suggest that the deformation of the fibrils (which controls the crack-growth kinetics) might be attributed to long-term relaxation processes such as reptation. This is quite surprising at first sight because below the melting point the craze fibrils consist of a network of crystalline blocks, which would prevent reptation from taking place within the fibril. However, as the craze fibrils are deforming plastically, chain transport through the crystals might be the dominant deformation mechanism. To verify this, the next logical step would be to determine the temperature dependence for the homopolymer grades because this will provide information about the type of deformation process that occurs within the fibril.

For completeness, Table 4 lists multilinear fits with various molecular weight moments, ranked according to the goodness of fit as characterized by the adjusted $R^{2}$ value. From this table, it follows that the best fit is obtained using $M_{\mathrm{w}}$ and $M_{\mathrm{z}}$ as variables, which shows a drastic improvement compared to the fit with just $M_{\mathrm{w}}$. It also shows that, in case $M_{\mathrm{z}}$ is unknown, a fit using $M_{\mathrm{n}}$ and $M_{\mathrm{w}}$ is still better than using $M_{\mathrm{w}}$ alone.

4.5. Temperature Dependence of Fatigue Crack Growth in Homopolymers. As shown in the previous section, the fatigue crack-growth kinetics of polyethylene homopolymers correlates strongly with the width-corrected $M_{\mathrm{w}}$. However, the exact deformation process that governs the crack-growth kinetics could not be determined from the correlation with the MWD alone. Hence, a series of
Table 4. Multilinear Fits with Various Molecular Weight Moments $^{a}$

\begin{tabular}{lcc}
\multicolumn{1}{c}{ variables } & $\bar{R}^{2}$ & \multicolumn{1}{c}{ model } \\
$M_{\mathrm{w}}, M_{\mathrm{z}}$ & 0.971 & $A / A_{0}=0.164\left(M_{\mathrm{w}}\left(M_{\mathrm{z}} / M_{\mathrm{w}}\right)^{-0.35}\right)^{-3.3}$ \\
$M_{\mathrm{n}}, M_{\mathrm{w}}, M_{\mathrm{z}}$ & 0.970 & $A / A_{0}=0.243\left(M_{\mathrm{w}}\left(M_{\mathrm{w}} / M_{\mathrm{n}}\right)^{0.05}\left(M_{\mathrm{z}} / M_{\mathrm{w}}\right)^{-0.26}\right)^{-3.3}$ \\
$M_{\mathrm{n}}, M_{\mathrm{w}}$ & 0.962 & $A / A_{0}=1.062\left(M_{\mathrm{w}}\left(M_{\mathrm{w}} / M_{\mathrm{n}}\right)^{-0.18}\right)^{-3.5}$ \\
$M_{\mathrm{w}}$ & 0.899 & $A / A_{0}=1.44 M_{\mathrm{w}}^{-3.4}$
\end{tabular}

${ }^{a_{T}}$ The first column lists the variables, the second column is the adjusted $R^{2}$ value (symbol $\bar{R}^{2}$ ) of the fit, and the last column is the corresponding model with the substituted fit parameters.

measurements were performed between 23 and $92{ }^{\circ} \mathrm{C}$ in order to obtain the activation energy, which would provide us with more information about the underlying deformation process. The crack-growth kinetics curves are shown as a function of temperature for HPE-12-75-350 in Figure 10a. As can be seen from these measurements, the crack-growth kinetics curves can still be properly described with a ParisErdogan exponent $m$ of 3.9. Hence, the prefactor $A$ can be used to describe the crack-growth kinetics at elevated temperatures as well. Additionally, measurements at elevated temperatures were performed for several homopolymer grades in order to determine if the activation energy depends on the MWD (see Table 2 in appendix C). The prefactor $A$ of these measurements are, therefore, shown as a function of the widthcorrected $M_{\mathrm{w}}$ in Figure $10 \mathrm{~b}$. The first important observation is that data points at all of the employed test temperatures follow exactly the same slope. The exponents of the optimal combined fit for the entire data set are close to the ones observed for the optimal fit of the room temperature data alone ( $p$ and $r$ are -3.3 and -0.37 respectively for the combined fit compared to -3.3 and -0.35 for the room temperature data alone) and fitting with the parameters found in 5.4.1 yields nearly identical curves with the same coefficient of determination $\left(R^{2}\right.$-value $)\left(R^{2}=0.974\right)$. This indicates that the relation with the width-corrected $M_{\mathrm{w}}$ is approximately the same for the investigated grades at all temperatures. This would suggest that the temperature dependence is likely to be independent of the width-corrected $M_{\mathrm{w}}$ and, therefore, also independent of the MWD.

A second observation that can be made from Figure $10 \mathrm{~b}$, is that the crack-growth kinetics are increasingly accelerated at temperatures above $60{ }^{\circ} \mathrm{C}$, which can be related to a change in activation energy. In order to show the change in activation energy more clearly, the prefactors $A$ of four homopolymer grades (HPE-12-75-350, HPE-4.4-197-1790, HPE-24-2822100 and HPE-21-320-1920) have been plotted as a function of reciprocal temperature in Figure 11a. As can be seen from Figure 11a, two slopes are visible for all four homopolymer grades: a moderate slope at relatively low temperatures and a steep slope at relatively high temperatures. In addition, it can be confirmed that the homopolymers shown in Figure 11a have the same temperature dependence over the entire range of test temperatures, which confirms that the temperature dependence is independent of molecular weight. This becomes even more obvious when the curves are shifted vertically to a single reference value at room temperature and the temperature shift factor $\left(\mathrm{a}_{T}\right)$ is plotted against reciprocal temperature, which is shown in Figure $11 \mathrm{~b}$. While some spread can be seen after the curves are shifted, it is evident from Figure $11 \mathrm{~b}$ that the temperature dependence curves of the homopolymers can be superimposed. From the superimposed curves, it can be 


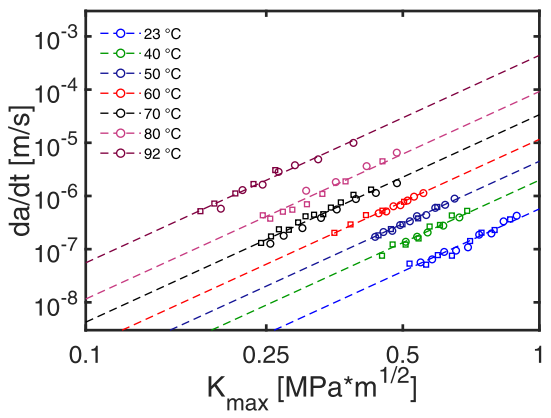

(a)

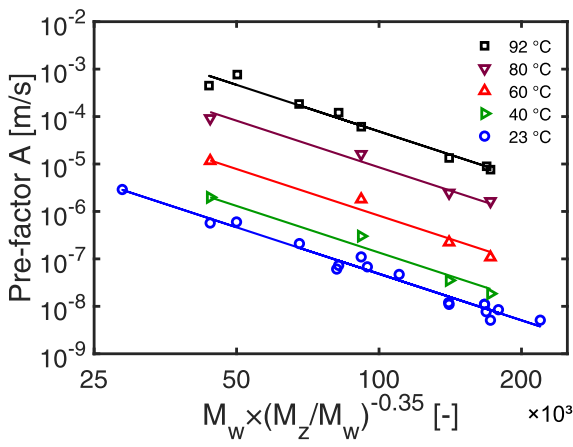

(b)

Figure 10. Log-log plots of (a) crack-growth rate versus stress intensity factor for the optimized single parameter fits of the Paris-Erdogan law with a constant Paris-Erdogan exponent of 3.9 for HPE-12-75-350 over a range of temperatures and (b) Paris-Erdogan prefactor $A$ versus the width-corrected $M_{\mathrm{w}}$ at $23{ }^{\circ} \mathrm{C}$ (blue), $40{ }^{\circ} \mathrm{C}$ (green), $60{ }^{\circ} \mathrm{C}$ (red), $80{ }^{\circ} \mathrm{C}$ (purple), and $92{ }^{\circ} \mathrm{C}$ (black). The markers are data points, while the dashed and solid lines are the optimized power-law fits of the data.

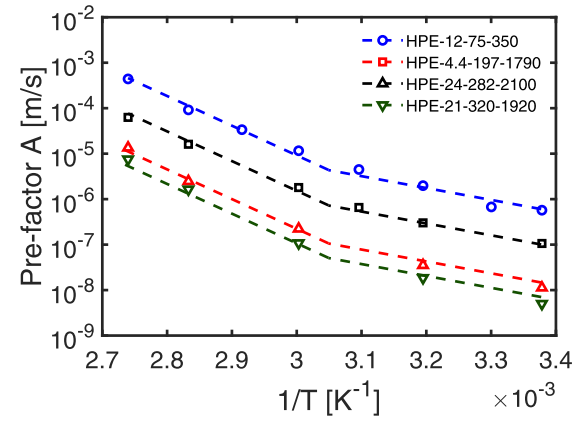

(a)

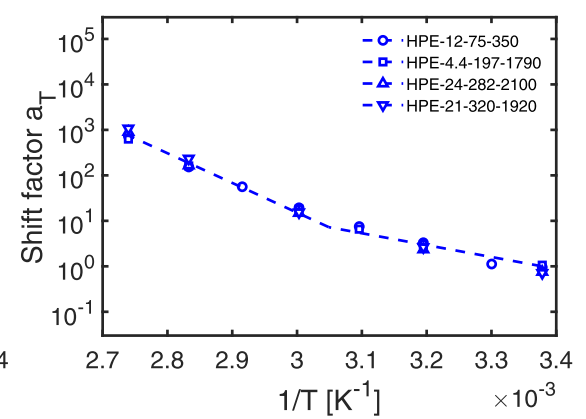

(b)

Figure 11. Semi-log plots of the (a) Paris-Erdogan prefactor $A$ and (b) temperature shift factor $a_{T}$ versus reciprocal temperature. The markers are data points, while the dashed lines are optimized using the Arrhenius equation. The activation energies are 50 and $125 \mathrm{~kJ} / \mathrm{mole}$ for the lowtemperature and high-temperature processes, respectively.

observed that the transition point lies at approximately $55{ }^{\circ} \mathrm{C}$. This corresponds well with the observations made by the group of Baer on medium density polyethylene ${ }^{32}$ and bimodal polyethylene. ${ }^{33}$ Calculation of the activation energies from the two slopes reveals an average value of $50 \mathrm{~kJ} / \mathrm{mole}$ for the low temperature process $\left(23{ }^{\circ} \mathrm{C}<T<55{ }^{\circ} \mathrm{C}\right)$, while the high temperature process $\left(T>55^{\circ} \mathrm{C}\right)$ showed an average activation energy of $125 \mathrm{~kJ} / \mathrm{mole}$. The value of the highest activation energy is similar to the one found by Parsons et al. ${ }^{32}$ for medium density polyethylene, who related the high temperature process to the $\alpha$-relaxation mechanism, which has a comparable activation energy. ${ }^{43,57-59}$ The activation energy found for the low temperature process is somewhat higher than the values found by the group of Baer, ${ }^{32,33}$ which could be related to the incorporation of co-monomer within the grades used in their research. This, together with the temperature and MWD dependence of bimodal copolymer grades, will be investigated in a subsequent publication.

From the activation energies it can be deduced that the deformation of the craze fibrils can most likely be attributed to chain slip (including chain disentanglement) ${ }^{22}$ because the activation energy of chain scission (approximately $430 \mathrm{~kJ}$ / mole) is far higher than the energies found in this section. Through chain slip, fibrils grow in length (and eventually fail) due to chains sliding along each other, losing contact points (entanglements, physical cross-links sustained by lamellar blocks) along the way. ${ }^{50-52}$ The slope of the molecular-weight dependence found in Section 4.4 can be explained by the chain-slip mechanism as well. Because it has been shown (by neutron scattering experiments) that there is no difference between the radius of gyration for long polyethylene chains in the melt and in the semi-crystalline state, it can be deduced that if no chain scission occurs, plastic deformation processes can only take place through a "snake-like" motion as proposed by the reptation theory. In this case, the $\alpha$-relaxation process in the crystals, as well as the entanglements in the amorphous phase, provide a "background viscosity" and a "tube mobility" that would be different from values found in the melt, ${ }^{60}$ but the molecular weight dependence would nevertheless be expected to be similar to reptation. A similar observation was made by Berger and Kramer $^{61}$ for high-temperature crazing of polystyrene, where craze growth was also found to be dominated by chain slip rather that chain fracture. Further support for reptation-like slip rather than chain fracture comes from molecular simulations by $\mathrm{Ge}$ et $\mathrm{al}^{62}$ of crazing in glassy polymers.

As discussed in the previous paragraphs, the high temperature process and low temperature process can be related to deformation processes in the crystalline and amorphous phase respectively. ${ }^{32,33,50-52}$ This would imply that the greatest contribution to the crack-growth kinetics at room temperature can be attributed to the low temperature process related to the amorphous phase. This would furthermore suggest that the influence of morphological parameters such as lamellar thickness would have relatively little influence on the crackgrowth kinetics at room temperature because these would 
Table 5. Molecular Parameters, Morphological Parameters, and Crack-Growth Kinetics for Different Processing Conditions; $R_{3.9}^{2}$ is the Coefficient of Determination for the Fit Using $m=3.9$

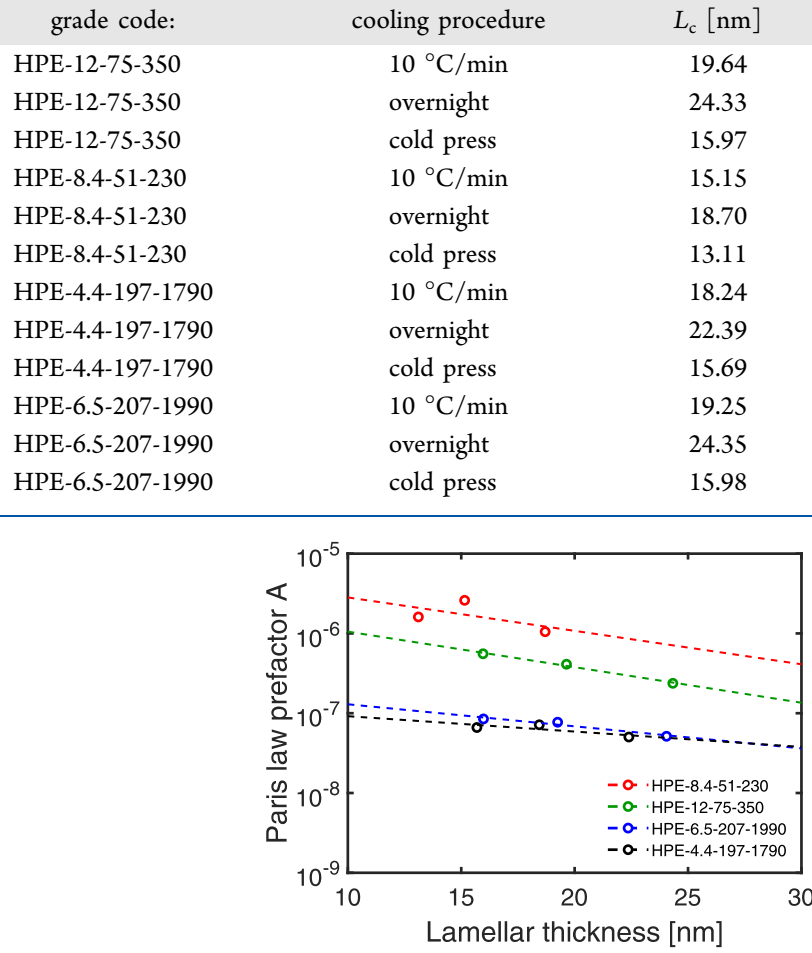

(a)

$\begin{array}{cccc}\chi_{\mathrm{v}}[\% \mathrm{v}] & T\left[{ }^{\circ} \mathrm{C}\right] & A_{3.9}[\mathrm{~m} / \mathrm{s}] & R_{3.9}^{2}[-] \\ 72.1 & 23 & 4.2 \cdot 10^{-7} & 0.975 \\ 76.1 & 23 & 2.4 \cdot 10^{-7} & 0.983 \\ 69.1 & 23 & 5.6 \cdot 10^{-7} & 0.974 \\ 67.0 & 23 & 2.6 \cdot 10^{-6} & 0.927 \\ 70.4 & 23 & 1.0 \cdot 10^{-6} & 0.874 \\ 65.7 & 23 & 1.7 \cdot 10^{-6} & 0.873 \\ 70.7 & 23 & 7.0 \cdot 10^{-8} & 0.973 \\ 72.6 & 23 & 5.1 \cdot 10^{-8} & 0.970 \\ 68.7 & 23 & 6.7 \cdot 10^{-8} & 0.988 \\ 70.3 & 23 & 7.9 \cdot 10^{-8} & 0.952 \\ 74.2 & 23 & 4.7 \cdot 10^{-8} & 0.978 \\ 68.5 & 23 & 8.3 \cdot 10^{-8} & 0.978\end{array}$

(b)

Figure 12. Semi-log plots of the Paris-Erdogan prefactor $A$ (a) and crystallinity (b) versus lamellar thickness for a selection of HDPE grades (see Table 3). The following grades are shown in the graph: HPE-8.4-51-230 (red), HPE-12-75-350 (green), BPE-6.5-207-1990 (blue), and HPE-4.4197-1790 (black). The dashed lines are optimized fits of the data.

predominantly influence the high temperature ( $\alpha$-relaxation) process. $^{43,57-59}$ In order to confirm this hypothesis, measurements were performed at different cooling rates for several selected grades. The results of these measurements will be discussed in the next section.

4.6. Influence of Processing Conditions on Fatigue Crack Growth Kinetics. As shown in the previous sections, the width-corrected $M_{\mathrm{w}}$ shows a good correlation with the crack-growth kinetics. However, unlike the TM fraction, the width-corrected $M_{\mathrm{w}}$ depicts no obvious correlation to the morphology of the material, even though significant variation in lamellar thickness can be observed among the HDPE grades processed at the same cooling rate. Nevertheless, the lamellar thickness governs the length of the lamellar blocks found within the craze fibrils, which in turn influences the rate of chains moving through the lamellar blocks. Therefore, an investigation into the influence of lamellar thickness on the crack-growth kinetics is warranted. Variation of the lamellar thickness was, in this case, achieved through the use of different cooling procedures, in order to eliminate the influence of the MWD. The relationship between the prefactor $A$ and the lamellar thickness at room temperature is shown for several grades in Table 5 and Figure 12a. In general, it can be seen that the prefactor $A$ shows a slight decrease with increasing lamellar thickness for all of the tested grades and that the decrease in the prefactor $A$ becomes (somewhat) greater when the $M_{\mathrm{w}}$ of the material decreases. Because an over-all linear curve is found between crystallinity and lamellar thickness for these samples, a comparable trend is expected when prefactor $A$ is plotted against crystallinity. The observed decrease of prefactor $A$ with lamellar thickness (or crystallinity) can be explained by the chain slip mechanism mentioned earlier ${ }^{2,50-52}$ because an increase in lamellar thickness should somewhat inhibit chain slip within the fibrils and, therefore, lower the prefactor $A$. However, the influence of lamellar thickness is rather small and does not interfere with the good correlation of the crack-growth kinetics with the width-corrected $M_{w}$, despite variation in the morphology of the sample. Because the high-temperature process can be related to $\alpha$-relaxation, which is known to be influenced by lamellar thickness, it can be anticipated that lamellar thickness will have a stronger influence at elevated temperatures. As a final note, the rather large amount of scatter seen for the lowest $M_{\mathrm{w}}$ material (HPE-8.4-51-230) can be attributed to the greater sensitivity to accelerated crack propagation for this grade.

\section{CONCLUSIONS}

The aim of this work is to investigate the effect of the MWD on the fatigue crack-growth kinetics in HDPE homopolymers. Crack-growth experiments on CT specimens are performed under cyclic loading (load ratio $=0.1$, frequency $=5 \mathrm{~Hz}$ ) at temperatures ranging between 23 and $92{ }^{\circ} \mathrm{C}$ in order to measure the crack-growth kinetics of HDPE homopolymers with systematic variations in $M_{\mathrm{n}}$ and $M_{\mathrm{w}}$. Through significant variation in specimen thickness, it is shown that the crackgrowth kinetics are largely independent of specimen geometry. Hence, linear elastic fracture mechanics is assumed to apply for all of the sample thicknesses used in this study. When plot on a log-log scale, the crack-growth kinetics curves can be described with a Paris-Erdogan law with the same exponent $m$ for all of 
the examined grades. The exponent $m$ is shown to be equal to $m=3.9$, which is close to a theoretical value of $m=4.0$ given by the Dugdale model. The foregoing also implies that the Paris-Erdogan prefactor $A$ is the governing parameter for the crack-growth kinetics. A rather poor correlation is subsequently observed when the prefactor $A$ is shown as a function of the TM fraction as derived by Huang and Brown. Using the average number of effective physical cross-links per chain, which contains the contribution of the entangled loops in addition to that of the TMs, provides a better, but not yet convincing, correlation with the crack-growth kinetics. A greatly improved correlation can, however, be seen when prefactor $A$ is plotted as a function of $M_{w}$. This correlation can be improved even further when $M_{\mathrm{w}}$ is adjusted by correcting for the width of the MWD. This is achieved by performing a parameter optimization, where it is shown that the ratio $M_{\mathrm{z}}$ / $M_{\mathrm{w}}$ can be used to correct $M_{\mathrm{w}}$ for the width of the MWD. The slope of the power-law correlation of prefactor $A$ with the width-corrected $M_{\mathrm{w}}$ is found to be equal to -3.3 . The temperature dependence was subsequently determined to identify the underlying mechanisms that govern deformation within the fibril. Analysis of the temperature dependence reveals the presence of two deformation processes: a hightemperature process related to $\alpha$-relaxation in the crystalline phase $(125 \mathrm{~kJ} / \mathrm{mole})$ and a low-temperature process related to an unspecified relaxation mechanism $(50 \mathrm{~kJ} / \mathrm{mole})$. As both processes have an activation energy lower than that required for chain scission $(430 \mathrm{~kJ} / \mathrm{mol})$, they are likely connected to chain slip. The absence of chain fracture combined with the observed large-strain plastic deformation in the craze fibrils are indicative of chain slip through crystals and entanglements, the latter of which could explain the observed molecular weight dependence similar to what is found for reptation. It is well known for the solid-state plastic deformation of polyethylene fibers that the maximum draw ratio is limited by the entanglement density and that crystal plasticity provides a background "viscosity". The present findings point in a similar direction. From elevated temperature experiments on various different grades, it was found that the molecular-weight distribution does not affect the temperature dependence of $A$. Moreover, the minor influence of the lamellar thickness on the prefactor $A$ shows that detailed morphological parameters have no great influence on crack-growth kinetics at room temperature.

\section{ASSOCIATED CONTENT}

\section{SI Supporting Information}

The Supporting Information is available free of charge at https://pubs.acs.org/doi/10.1021/acs.macromol.1c01945.

Molecular, morphological, and crack-growth kinetics parameters of HDPE polymers; average number of effective physical cross-links per chain; crack-growth kinetics of HDPE polymers as a function of test temperature; and representation of the Paris-Erdogan relation $(\mathrm{PDF})$

\section{AUTHOR INFORMATION}

\section{Corresponding Authors}

Theo A. Tervoort - Department of Materials, ETH Zürich, 8093 Zürich, Switzerland; (i) orcid.org/0000-0002-49629841; Email: tervoort@ethz.ch
Leon E. Govaert - Department of Mechanical Engineering, Eindhoven University of Technology, 5600 MB Eindhoven, The Netherlands; Faculty of Engineering Technology, University of Twente, 7500AE Enschede, The Netherlands; Email: 1.e.govaert@tue.nl

\section{Authors}

Robin R.J. Cerpentier - Department of Mechanical Engineering, Eindhoven University of Technology, 5600 MB Eindhoven, The Netherlands

Tim van Vliet - Department of Mechanical Engineering, Eindhoven University of Technology, 5600 MB Eindhoven, The Netherlands

Leonid V. Pastukhov - Department of Mechanical Engineering, Eindhoven University of Technology, 5600 MB Eindhoven, The Netherlands

Martin van Drongelen - Faculty of Engineering Technology, University of Twente, 7500AE Enschede, The Netherlands; (1) orcid.org/0000-0002-3789-8657

Mark J. Boerakker - SABIC, Technology Centre Geleen, 6167 RD Geleen, The Netherlands

Complete contact information is available at:

https://pubs.acs.org/10.1021/acs.macromol.1c01945

\section{Notes}

The authors declare no competing financial interest.

\section{ACKNOWLEDGMENTS}

The authors thank Dr. Nic. Friederichs (SABIC) for kindly providing a unique set of polyethylene homopolymers. Dr. Enrico Troisi, Dr. Harm Caelers, and Dr. Rudy Deblieck all from SABIC are acknowledged for fruitful discussions. R.R.J.C. gratefully acknowledges funding by SABIC.

\section{REFERENCES}

(1) Huang, Y.-L.; Brown, N. The effect of molecular weight on slow crack growth in linear polyethylene homopolymers. J. Mater. Sci. 1988, 23, 3648-3655.

(2) Tervoort, T. A.; Visjager, J.; Smith, P. On abrasive wear of polyethylene. Macromolecules 2002, 35, 8467-8471.

(3) Schulte, U. A vision becomes true: 50 years of pipes made from High Density Polyethylene. In Proceedings of Plastic Pipes XIII. Washington, 2006.

(4) Gabriel, L. H. Corrugated Polyethylene Pipe Design Manual and Installation Guide; Plastic Pipe Institute: USA, 2011; Chapter 1.

(5) Andersson, U. Which factors control the lifetime of plastic pipes and how the lifetime can be extrapolated. In Proceedings of Plastic Pipe XI, 2001.

(6) Gedde, U. W.; Viebke, J.; Leijström, H.; Ifwarson, M. Long-term properties of hot-water polyolefin pipes-a review. Polym. Eng. Sci. 1994, 34, 1773-1787.

(7) Lang, R. W.; Stern, A.; Doerner, G. Prediction Models for Thermoplastics Pipes Under Internal Pressure. Angew. Makromol. Chem. 1997, 247, 131-145.

(8) Brown, N.; Donofrio, J.; Lu, X. The transition between ductile and slow-crack-growth failure in polyethylene. Polymer 1987, 28, $1326-1330$.

(9) Lustiger, A.; Markham, R. L. Importance of tie molecules in preventing polyethylene fracture under long-term loading conditions. Polymer 1983, 24, 1647-1654.

(10) Pinter, G.; Haager, M.; Balika, W.; Lang, R. W. Cyclic crack growth tests with $\mathrm{CRB}$ specimens for the evaluation of the long-term performance of PE pipe grades. Polym. Test. 2007, 26, 180-188.

(11) Lu, X.; Wang, X.; Brown, N. Slow fracture in a homopolymer and copolymer of polyethylene. J. Mater. Sci. 1988, 23, 643-648. 
(12) Chan, M. K. V.; Williams, J. G. Slow stable crack growth in high density polyethylenes. Polymer 1983, 24, 234-244.

(13) Kanters, M. J. W.; Remerie, K.; Govaert, L. E. A new protocol for accelerated screening of long-term plasticity-controlled failure of polyethylene pipe grades. Polym. Eng. Sci. 2016, 56, 676-688.

(14) Jar, P. Y. B. Revisiting creep test on polyethylene pipe-Data analysis and deformation mechanisms. Polym. Eng. Sci. 2021, 61, 586-599.

(15) Popli, R.; Mandelkern, L. Influence of structural and morphological factors on the mechanical properties of the polyethylenes. J. Polym. Sci., Part B: Polym. Phys. 1987, 25, 441-483.

(16) Cerpentier, R. R. J. Influence of molecular and morphological parameters on the long-term performance of high-density polyethylene. Ph.D. Thesis, Technische Universiteit Eindhoven, Department of Mechanical Engineering, 2020.

(17) Wunderlich, B.. Macromolecular Physics - Crystal Melting, 1st ed.; Academic Press, 1980; Vol. 3.

(18) Lustiger, A.; Corneliussen, R. D. The role of crazes in the crack growth of polyethylene. J. Mater. Sci. 1987, 22, 2470-2476.

(19) Kausch, H.-H.; Michler, G. H. Intrinsic Molecular Mobility and Toughness of Polymers I, Kausch, H.-H., Ed.; Springer Berlin Heidelberg: Berlin, Heidelberg, 2005, pp 1-33.

(20) Deblieck, R. A. C.; van Beek, D. J. M.; Remerie, K.; Ward, I. M. Failure mechanisms in polyolefines: The role of crazing, shear yielding and the entanglement network. Polymer 2011, 52, 2979-2990.

(21) Huang, Y.-L.; Brown, N. Dependence of slow crack growth in polyethylene on butyl branch density: morphology and theory. $J$. Polym. Sci., Part B: Polym. Phys. 1991, 29, 129-137.

(22) Brown, N.; Lu, X. A fundamental theory for slow crack growth in polyethylene. Polymer 1995, 36, 543-548.

(23) Lu, X.; Ishikawa, N.; Brown, N. The critical molecular weight for resisting slow crack growth in a polyethylene. J. Polym. Sci., Part B: Polym. Phys. 1996, 34, 1809-1815.

(24) Yeh, J. T.; Runt, J. Fatigue crack propagation in high-density polyethylene. J. Polym. Sci., Part B: Polym. Phys. 1991, 29, 371-388.

(25) DesLauriers, P. J.; Rohlfing, D. C. Estimating Slow Crack Growth Performance of Polyethylene Resins from Primary Structures such as Molecular Weight and Short Chain Branching. Macromol. Symp. 2009, 282, 136-149.

(26) García, R. A.; Carrero, A.; Martín, C.; Domínguez, C. Effects of the structural components on slow crack growth process in polyethylene blends. Composition intervals prediction for pipe applications. J. Appl. Polym. Sci. 2011, 121, 3269-3276.

(27) Zhou, Y.; Lu, X.; Brown, N. A fatigue test for controlling the quality of polyethylene copolymers. Polym. Eng. Sci. 1991, 31, 711716.

(28) Zhou, Z.; Brown, N. Slow crack growth of blends of high density and linear low density polyethylenes as influenced by morphology. Polymer 1994, 35, 3619-3623.

(29) Zhou, Z.; Lu, X.; Brown, N. The effect of blending high-density and linear low-density polyethylenes on slow crack growth. Polymer 1993, 34, 2520-2523.

(30) Fodor, J. S.; Lamborn, M. J.; DesLauriers, P. J. Correlating polyethylene microstructure to stress cracking: Development of primary structure parameters. Polymer 2018, 147, 8-19.

(31) Frank, A.; Pinter, G.; Lang, R. W. Prediction of the remaining lifetime of polyethylene pipes after up to 30 years in use. Polym. Test. 2009, 28, 737-745.

(32) Parsons, M.; Stepanov, E. V.; Hiltner, A.; Baer, E. Correlation of fatigue and creep slow crack growth in a medium density polyethylene pipe material. J. Mater. Sci. 2000, 35, 2659-2674.

(33) Zhou, Z.; Hiltner, A.; Baer, E. Predicting long-term creep failure of bimodal polyethylene pipe from short-term fatigue tests. J. Mater. Sci. 2011, 46, 174-182.

(34) Bucknall, C. B.; Dumpleton, P. Fatigue Crack Growth in Polyethylene. Polym. Eng. Sci. 1985, 25, 313-317.

(35) Zhou, Y.-Q.; Brown, N. The mechanism of fatigue failure in a polyethylene copolymer. J. Polym. Sci., Part B: Polym. Phys. 1992, 30, 477-487.
(36) Kadota, K.; Chum, S.; Chudnovsky, A. Bridging the PE lifetime under fatigue and creep conditions with its crystallization behavior. $J$. Appl. Polym. Sci. 1993, 49, 863-875.

(37) Zhou, Y.; Brown, N. Anomalous fracture behaviour in polyethylenes under fatigue and constant load. J. Mater. Sci. 1995, 30, 6065-6069.

(38) Redhead, A.; Frank, A.; Pinter, G. Investigation of slow crack growth initiation in polyethylene pipe grades with accelerated cyclic tests. Eng. Fract. Mech. 2013, 101, 2-9.

(39) ISO Central Secretary. Polyethylene (PE) Materials for Piping Systems - Determination of Resistance to Slow Crack Growth under Cyclic Loading- Cracked Round Bar Test Method; Standard ISO/IEC TR 18489, 2015; p 2015.

(40) Caelers, H. J. M. Structure tuning for enhanced properties in isotactic polypropylene. Ph.D. Thesis, Technische Universiteit Eindhoven, Department of Mechanical Engineering, 2017.

(41) Humbert, S.; Lame, O.; Vigier, G. Polyethylene yielding behaviour: What is behind the correlation between yield stress and crystallinity. Polymer 2009, 50, 3755-3761.

(42) ASTM E647 Standard Test Method for Measurement of Fatigue Crack Growth Rates; American Society for Testing and Materials, 2014; Vol. 03, pp 1-50.

(43) Kanters, M. J. W. Prediction of long-term performance of loadbearing thermoplastics. Ph.D. thesis, Technische Universiteit Eindhoven, Department of Mechanical Engineering, 2015.

(44) Parsons, M.; Stepanov, E. V.; Hiltner, A.; Baer, E. Correlation of stepwise fatigue and creep slow crack growth in high density polyethylene. J. Mater. Sci. 1999, 34, 3315-3326.

(45) Seguela, R. Critical review of the molecular topology of semicrystalline polymers: The origin and assessment of intercrystalline tie molecules and chain entanglements. J. Polym. Sci., Part B: Polym. Phys. 2005, 43, 1729-1748.

(46) Harcup, J. P.; Duckett, R. A.; Ward, I. M.; Capaccio, G. Fatigue crack growth in polyethylene: material dependence. I: tensile/ compressive loading. Polym. Eng. Sci. 2000, 40, 627-634.

(47) Sauer, J. A.; Foden, E.; Morrow, D. R. Influence of molecular weight on fatigue behavior of polyethylene and polystyrene. Polym. Eng. Sci. 1977, 17, 246-250.

(48) Bersted, B. H.; Anderson, T. G. Influence of molecular weight and molecular weight distribution on the tensile properties of amorphous polymers. J. Appl. Polym. Sci. 1990, 39, 499-514.

(49) Prentice, P. Influence of molecular weight on the fracture of poly(methyl methacrylate) (PMMA). Polymer 1983, 24, 344-350.

(50) Wilding, M. A.; Ward, I. M. Tensile creep and recovery in ultrahigh modulus linear polyethylenes. Polymer 1978, 19, 969-976.

(51) Wilding, M. A.; Ward, I. M. Creep and recovery of ultra high modulus polyethylene. Polymer 1981, 22, 870-876.

(52) Ward, I. M.; Wilding, M. A. Creep behavior of ultrahighmodulus polyethylene: Influence of draw ratio and polymer composition. J. Polym. Sci., Polym. Phys. Ed. 1984, 22, 561-575.

(53) Ott, L. An Introduction to Statistical Methods \& Data Analysis; Cengage Learning: Boston, MA, 2016.

(54) de Gennes, P. G. Reptation of a polymer chain in the presence of fixed obstacles. J. Chem. Phys. 1971, 55, 572-579.

(55) Doi, M. Explanation for the 3.4-power law for viscosity of polymeric liquids on the basis of the tube model. J. Polym. Sci., Polym. Phys. Ed. 1983, 21, 667-684.

(56) des Cloizeaux, J. Relaxation and viscosity anomaly of melts made of long entangled polymers: time-dependent reptation. Macromolecules 1990, 23, 4678-4687.

(57) Boyd, R. H. Relaxation processes in crystalline polymers: experimental behaviour - a review. Polymer 1985, 26, 323-347.

(58) Sedighiamiri, A.; Govaert, L. E.; Kanters, M. J. W.; van Dommelen, J. A. W. Micromechanics of semicrystalline polymers: yield kinetics and long-term failure. J. Polym. Sci., Part B: Polym. Phys. 2012, 50, 1664-1679.

(59) Pegoretti, A.; Ashkar, M.; Migliaresi, C.; Marom, G. Relaxation processes in polyethylene fibre-reinforced polyethylene composites. Compos. Sci. Technol. 2000, 60, 1181-1189. 
(60) Smith, P.; Lemstra, P. J.; Booij, H. C. Ultradrawing of highmolecular-weight polyethylene cast from solution. II. Influence of initial polymer concentration. J. Polym. Sci., Polym. Phys. Ed. 1981, 19, 877-888.

(61) Berger, L. L.; Kramer, E. J. Chain Disentanglement during High-Temperature Crazing of Polystyrene. Macromolecules 1987, 20, 1980-1985.

(62) Ge, T.; Tzoumanekas, C.; Anogiannakis, S. D.; Hoy, R. S.; Robbins, M. O. Entanglements in glassy polymer crazing: Cross-links or tubes? Macromolecules 2017, 50, 459-471.

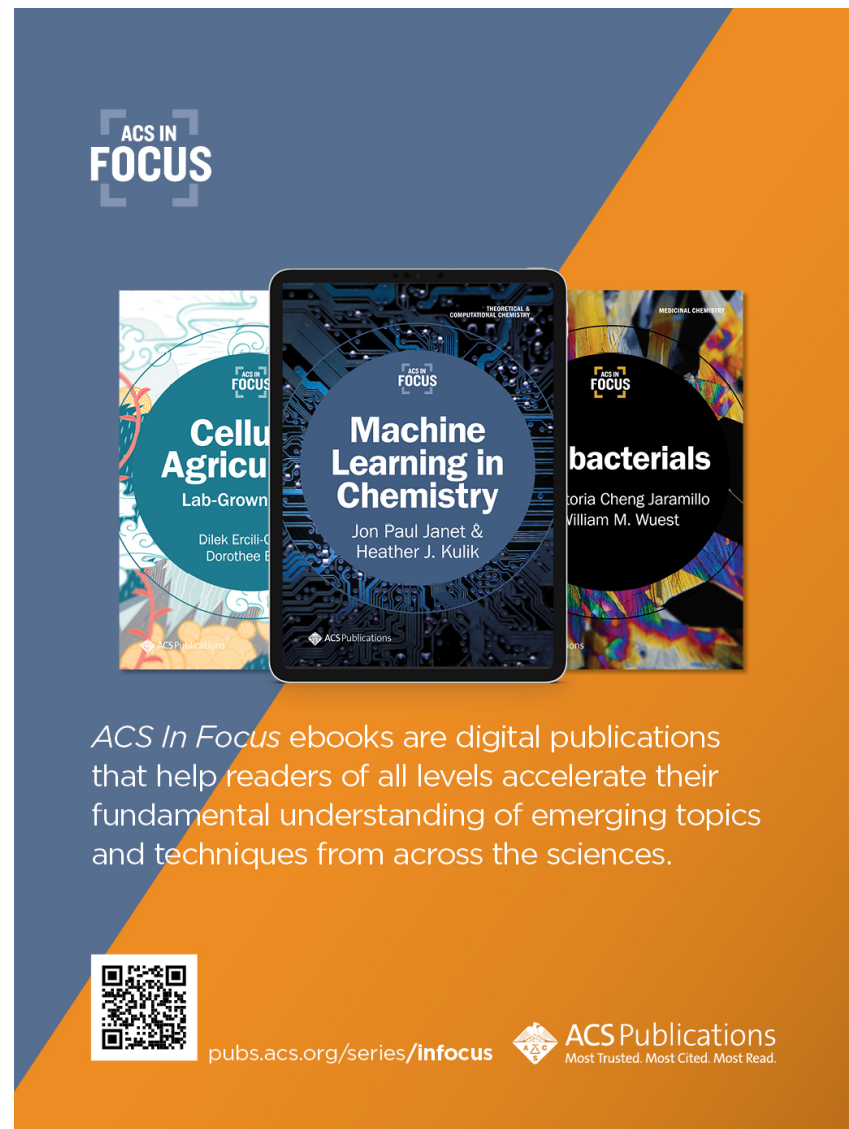

